\title{
1 Long-term topical corticosteroid use and risk of skin 2 cancer: A systematic review
}

\section{Executive Summary}

5 Background: Topical corticosteroids (TCS) are one of the most commonly prescribed medicines in dermatology and the mainstay of atopic dermatitis treatment and other skin conditions such as psoriasis. They are often required for months or years to control the disease and ultimately restore patients' quality of life. In some patients, TCS may have a local immunosuppressive effect and theoretically may increase the risk of skin cancer, whilst on the other hand TCS may decrease the risk of skin cancer in patients where TCS are used to treat inflammatory skin disease. To date no systematic review has been performed to collate evidence of the effect of long-term TCS use on the risk of skin cancer.

Objectives: The objective of this systematic review was to synthesize the available research evidence to determine the risk of skin cancer in patients on long-term use of TCS.

Inclusion Criteria:

\section{Types of participants}

This review considered studies that included people, of all ages, genders and ethnicities. Participants with HIV, transplant participants or participants with genetic diseases (for example Gorlin-Goltz syndrome) were also considered eligible for the review.

\section{Types of intervention}

This review considered studies that evaluate long-term use of topical corticosteroids. We define here 'long-term' as using TCS more than once a week for a month or longer.

\section{Types of studies}

This review considered cohort, cross-sectional and case-control observational studies exploring an 
Types of outcomes

The primary outcome measures of interest were: non-melanoma skin cancer (keratinocyte carcinoma), cutaneous squamous cell carcinoma (cSSC), basal cell carcinoma (BCC) or melanoma skin cancer. Genital and oral skin cancers are considered to be slightly different so we did not include them in this review.

Search Strategy: We performed a comprehensive search of MEDLINE, EMBASE and LILACS in February 2016 on $9^{\text {th }}$ November 2017 to identify observational epidemiological studies assessing the associations between long-term TCS use and skin cancer. We also searched EThOS at the British library (http://ethos.bl.uk) and three drug safety databases to identify unpublished work. The titles, abstracts and full text identified from the search were assessed independently by two authors against pre-specified inclusion/exclusion criteria.

Methodological Quality: Methodological quality was not assessed as no articles were found which met the inclusion criteria.

Data extraction: Data extraction was not possible as no articles were found which met the inclusion criteria.

Data Synthesis: It was not possible to complete data synthesis as no articles were found which met the inclusion criteria.

Results: A total of 1703 potentially relevant studies were identified following a comprehensive electronic search. After abstract and title screening, 51 full texts were assessed for eligibility criteria. Of these, no study met the inclusion criteria. No additional records were identified from searching unpublished literature.

Conclusions: We did not find any studies that might help us establish if long-term TCS use is associated with skin cancer. Future research using primary care databases might give a better understanding regarding long-term use of TCS and skin cancer.

53 Keywords: Basal cell carcinoma; melanoma; non-melanoma; squamous cell carcinoma; topical 54 corticosteroids. 
55

56

57

58

59

60

61

62

63

64

65

66

67

68

69

70

71

72

73

74

75

76

\section{Background}

Topical corticosteroids (TCS) are used to reduce inflammation and are one of the most commonly prescribed medicines in dermatology. They were first used successfully by Sulzberger and Witten in 1952 and their success marked a cornerstone in the history of dermatology. ${ }^{1}$ Topical corticosteroids are the mainstay of atopic dermatitis treatment and used for other skin conditions such as psoriasis, where they are often required for months or years to control the disease and ultimately restore patients' quality of life. Numerous TCS are now available in different preparations, concentrations and potencies; however, when used appropriately TCS efficacy and safety are well established. ${ }^{2-6}$

The beneficial anti-inflammatory effects of TCS are complex, being largely mediated via the cytoplasmic steroid receptor and involving actions on circulating cellular and cytokine mediators of inflammation as well as on the peripheral vasculture. ${ }^{7}$ The use of TCS is tempered by consideration of local and less frequently encountered systemic side effects. Known local side effects include skin atrophy, skin striae, contact allergy, rosacea, acne, mild hypopigmentation and hypertrichosis. Rarely absorption through the skin can cause adrenal suppression, hyperglycaemia and glaucoma. ${ }^{8}$ The risk of developing side effects is related to the potency, preparation, frequency and duration of use as well as and the age of the patient and the size of the surface area that the TCS is being applied to, or whether the area is vascular or not. In clinical practice these side effects are uncommon when TCS are used within their guidance.

There are two types of skin cancers: melanoma and non-melanoma (keratinocyte). Around $97 \%$ of skin cancers are non-melanoma (NMSC), comprising mainly of basal cell carcinomas (BCCs) or cutaneous squamous cell carcinomas (cSCCs). The incidence of NMSC is increasing worldwide ${ }^{9-13}$ with an estimated 2-3 million new cases of NMSC recorded each year. ${ }^{14}$ With respect to cutaneous malignant melanoma (CMM), this is the most serious form of skin cancer and has been increasing steadily in incidence over the past 30 years. ${ }^{15}$ Mortality due to CMM is much higher than that of NMSC. ${ }^{16}$

There are several observational studies that have looked at the relative risk of developing skin cancer due to oral corticosteroid exposure. ${ }^{17-18}$ These studies have provided conflicting results as to whether corticosteroids are associated with an increased risk of skin cancer. Karagas et al. ${ }^{17}$ conducted a casecontrol study on over 800 non-transplant cSSC and BCC patients. 17 The authors found that oral glucocorticoids may increase the risk of non-melanoma skin cancers, whereas Baibergenova et al. found no association between non-melanoma skin cancers and oral corticosteroids in a follow-up study of a chemotherapy trial with 1051 study participants. ${ }^{18}$ These studies highlight the clinical equipoise that exists around the impact oral corticosteroids have on the risk of skin cancer. 
There have been several epidemiological studies that have explored the risk of cancer specifically amongst atopic dermatitis patients. Hagwstromer et al. conducted a hospital-based study on 15666 patients with atopic dermatitis in Sweden between 1965 and 1999. ${ }^{19}$ The authors reported men faced a $50 \%$ increased risk of non-melanoma skin cancer during the first 10 years of follow-up, but this did not reach statistical significance. The authors did not look at the association between skin cancer and corticosteroid use ${ }^{19}$ Wang et al. conducted a review of atopic dermatitis studies published before 2004 and found no consistent associations were observed for skin cancers. ${ }^{20}$ This review did not look at the effect of TCS use on the risk of skin cancer. At present, it is not known what particular impact TCS have on the risk of skin cancer in the atopic dermatitis population.

With regards the organ transplant population, it is well established that immunosuppression increases the risk of skin malignancy. ${ }^{21,22}$ This occurs when oral corticosteroids are used, although most studies include patients treated with a combination of systemic immunosuppressants including azathioprine and calcineurin inhibitors. ${ }^{23,24}$ Oral corticosteroids are known to have an immunosuppressive effect, and TCS may have a local immunosuppressive effect. $\frac{25,26}{2}$ It is not known whether TCS may increase the risk of skin cancer through this mechanism.

On the other hand, it is possible that treating skin inflammation with TCS may reduce the risk of skin cancer. Several systematic reviews and meta-analyses report the benefits of anti-inflammatory drugs in reducing the risk of cancer, including skin cancers. ${ }^{27,275,26}$ The management of certain types of inflammatory skin diseases includes the rationale that reducing inflammation reduces the risk of cSCC development in vulval and penile lichen sclerosus as well as hypertrophic lichen planus. It is also known that chronic inflammation is a risk for the development of cSCC, such as in chronic ulceration and the development Marjolin's ulcer. ${ }^{29,307,28}$ This mainly holds true for CSCC but less is known about BCC and melanoma. .Therefore, overall TCS may decrease the risk of skin cancer in patients where TCS are used to treat inflammatory skin disease.

To date, no published systematic review or meta-analysis have been performed to collate evidence on long-term TCS use on the risk of skin cancer. The review group examined MEDLINE and EMBASE, Prospero and JBI Database of Systematic Reviews and Implementation Reports and did not find any current or planned reviews on the same topic. Immunosuppression induced by TCS, either local or systemic, may allow these cancers to emerge from reduced immunosurveillance. However, TCS may also reduce the risk of skin cancer in patients where TCS are used to treat inflammatory skin disease. With TCS use being one of the most commonly prescribed drugs in the clinical field of dermatology and the increasing incidence of skin cancer there is a need to review all current evidence about the possible association. The protocol for this systematic review has recently been published. $\underline{3129}$ 


\section{Review question}

122 The objective of this systematic review was to synthesize the available research evidence to determine

the risk of skin cancer in patients on long-term use of topical corticosteroids.

In people using long-term (more than once a week regular use over for onet month or longer) topical corticosteroids what is the risk of developing skin cancer (clinically or histologically confirmed nonmelanoma skin cancer (keratinocyte carcinoma), basal cell carcinoma, cutaneous squamous cell carcinoma or melanomat?

\section{Methods}

\section{Inclusion criteria}

\section{Participants}

This review considered studies that included people, of all ages, genders and ethnicities. Participants with HIV, transplant participants or participants with genetic diseases (for example Gorlin-Goltz syndrome) were also considered eligible for the review.

\section{Exposure of interest}

This review considered studies that evaluate long-term use of topical corticosteroids. We define here 'long-term' as using TCS more than once a week for a month or longer.

\section{Outcome or response}

This review considered studies that included the following outcome measures: Non-melanoma skin cancer (NMSC) (new nomenclature keratinocyte carcinoma), cutaneous squamous cell carcinoma (CSSC), basal cell carcinoma (BCC) or melanoma skin cancer. These outcomes could be measured by a clinical diagnosis and where available histological confirmation. Pre-cursors such as Bowen's disease were considered secondary outcomes.

\section{Study types}

This review considered analytical comparative observational studies including prospective and retrospective cohort studies, case-control studies and cross-sectional studies.

\section{Search strategy}

The search strategy aimed to identify both published and unpublished studies. A three-step search 
strategy was utilized in this review. An initial limited search of MEDLINE and EMBASE was undertaken followed by an analysis of the text words contained in the title and abstract, and of the index terms used to describe the article. A second search using identified key words and index terms was used to develop a comprehensive search strategy. The search strategy for MEDLINE is detailed in Appendix 1. Studies published in all languages were included.

\section{Information Sources}

The electronic databases searched included: MEDLINE, EMBASE and LILACS all from inception to $16^{\text {th }}$ February $20169^{\text {th }}$ November 2017. The search strategy for MEDLINE and LILACS are detailed in Appendix 1 and 2 respectively. The search for unpublished studies included: EThOS at the British library (http://ethos.bl.uk); Drug Consumption Database (http://www.imiprotect.eu/frameworkRep.shtml); =VigiBase (http://www.umcproducts.com/DynPage. aspx?id=73590\&mn1=1107\&mn2=1132

http://www.umc-products.com/DynPage.aspx?id=73567\&mn1=1107\&mn2=1132\&mn3=6052) and PROTECT ADR Database (http://www.imi-protect.eu/methodsRep.shtml)

\section{Study selection}

Following the search, all identified citations were collated and uploaded in EndNote and duplicates removed. Titles and abstracts were then screened by two independent reviewers (SR and EBT) for assessment against the inclusion criteria for the review. The full text of selected citations were retrieved and assessed independently by two reviewers (SR and EBT) in detail against the inclusion criteria. Full text studies that did not meet the inclusion criteria were excluded and reasons for exclusion were provided. Any disagreements between SR and EBT were resolved by discussion with reviewers JLB and FBH.

\section{Results}

\section{Description of studies}

Following a comprehensive and systematic literature search of the identified databases, 21981703 results were found (after excluding 27 duplicates). Titles and abstracts were then reviewed against the inclusion criteria and a further $2 \underline{201} 1$ duplicates were concurrently removed. A total of $5 \underline{2} 1$ articles were obtained for full review and reasons for exclusion are detailed in Figure 1. We contacted the authors for one study in order to clarify TCS exposure; as their study was the most relevant to our research question. ${ }^{32} \theta$ Unfortunately we got no response from the authors. No studies were found which met the inclusion criteria. Meta-synthesis of findings was therefore not possible. 


\section{Data extraction, Critical appraisal and Data synthesis}

186 As no eligible studies were identified, the process of data extraction, appraisal and synthesis as outlined in the a priori protocol (JBISRIR-2016-003226) were not required.

\section{Findings of the review}

190 No studies which met the inclusion criteria were found in this systematic review.

\section{Discussion}

The overall objective of this quantitative systematic review was to establish if there is an association between long-term TCS use and the risk of skin cancer. We hoped this review might be used to inform clinicians and patients of potential adverse effects of this treatment, or conversely to minimize unfounded fears of TCS use which is common and often called 'steroid phobia' in the dermatology community. $3 \underline{3}+1$

197 There were no relevant studies which meant that this objective was not achieved. Several papers 198 were identified which included oral and genital sites;34-612-59 however, these are considered 'special sites' because disease presentation and risk factors are different to that of other sites of the body and therefore a specific review would be needed in the context of this clinical area. A number of excluded studies merit discussion to place these findings, or lack of, in context in order to inform future research and current clinical evidence based practice.

203 The study by Landi et al. ${ }^{32 \vartheta}$ was the only one study identified which had a primary objective of 204 determining whether steroid treatment was associated with skin cancer. However this study did not meet our eligibility criteria as there was no information on frequency and duration of TCS exposure. The authors conducted a case-control study in Italy, from 1994 to 1999, which included patients with cutaneous malignant melanoma (cases) and those without the condition (controls); glucocorticoid (GC) exposure was measured. People with malignant melanoma were less likely to have used GCs $(\mathrm{OR}=0.39 ; 95 \% \mathrm{Cl}=0.20-0.74 ; \mathrm{n}=362$ ). To overcome confounding by indication, the authors assessed whether the association between GC use and melanoma could be affected by treatment for dermatologic diseases in comparison to treatment for more systemic health problems. The authors also explored whether the occurrence of melanoma varied by route of administration (oral vs. topical) and they took into account ascertainment bias by adjusting for frequency of moles removed in

214 addition to other covariates. The authors concluded that people without melanoma were more likely to 
have been exposed to glucocorticoid-based therapy than those with melanoma; there was no effect modification by reason for treatment or route of administration. Larger studies would be needed to confirm these findings.

There were three studies which investigated the risk of skin cancer amongst people with dermatological conditions. Ming et al. ${ }^{6 \underline{20}}$ conducted a case-control study in the US, between 1998 and 2001, with 1378 NMSC cases and 1533 controls with other dermatologic conditions to explore whether people with NMSC are more likely to have had atopic dermatitis (AD) than those without NMSC. The authors report TCS use was a confounder for the association between AD and NMSC. After adjusting for age, sex, ethnicity and TCS use the odds of AD was $0.78(96 \% \mathrm{Cl} 0.61,0.98)$ for those who had NMSC compared to those who did not. The authors also conducted a secondary analysis and report the odds of being a TCS user was about $30 \%$ less in those with a NMSC as compared with those without a NMSC. However, again, no information on frequency of TCS use was available, a limitation cited by the authors.

Chen et al. ${ }^{631}$ investigated the risk of different cancers in people with psoriasis using the Taiwan National Health Insurance Research Database. Skin cancer was associated with psoriasis, especially younger patients, however the risk did not vary by topical treatment use (all topical treatments were grouped together). Finally, a Dutch cohort study with over 13,000 eczema and psoriasis patients showed the risk of skin cancer is not increased in those taking coal tar compared to those taking dermatocorticosteroids (all steroid treatments were grouped together). ${ }^{642}$

\section{Limitations}

The inclusion criteria for this review focused on patients who were exposed to long-term TCS use (more than once a week for a month or longer). There were no studies whose primary objective was to investigate long-term TCS exposure per se, as opposed to any TCS use. It is therefore unsurprising that no study included information on both duration and frequency of use. We believe that using a specific definition of long-term use based on clinical experience was necessary to maximize the external validity of this review.

\section{Conclusion}

We did not find any studies that might help us establish if long-term TCS use is associated with skin cancer. Future research using primary care databases might give a better understanding regarding long-term use of TCS and skin cancer.

\section{Implications for practice}


There was an absence of evidence identified in the review to make clinical recommendations.

\section{Implications for research}

There is a significant gap in the evidence base in the area of long-term TCS use and the risk of skin cancer, and therefore future research needs to be conducted to answer this important question. There are several published papers in the area of oral and genital sites, therefore a systematic review in this specific area could be of potential benefit to the dermatology community.

\section{Conflicts of interest}

The review team has no conflicts of interest.

Acknowledgements: The review team would like to thank information specialists Ms Liz Doney and Dr Douglas Grindlay for their help with developing the search strategies, and Dr Tessa Langley for her help with translating the German paper.

\section{Figure 1: PRISMA Flow Diagram of Study Selection}

\section{References}

1. Daniel BS, Orchard D. Ocular side-effects of topical corticosteroids: what a dermatologist needs to know. Australas J Dermatol. 2015;56(3):164-9.

2. Hoare $\mathrm{C}$, Li Wan Po A, Williams H. Systematic review of treatments for atopic eczema. Health Technology Assessment. 2001;4(37):191.

3. McHenry PM, Williams HC, Bingham EA. Fortnightly Review: Management of atopic eczema. BMJ 1995; 310(6983):843-7.

4. Van Der Meer JB, Glazenburg EJ, Mulder PG, Eggink HF, Coenraads PJ. The management of moderate to severe atopic dermatitis in adults with topical fluticasone propionate. The Netherlands Adult Atopic Dermatitis Study Group. Br J Dermatol. 1999; 140(6):111 $\underline{54-21 . ~}$

5. Berth-Jones J, Damstra RJ, Golsch S, Livden JK, Van Hooteghem O, Allegra F, et al. Twice weekly fluticasone propionate added to emollient maintenance treatment to reduce risk of relapse in atopic dermatitis: randomised, double blind, parallel group study. BMJ. 2003-200306-19 20:20:33;326(7403):1367.

6. Furue M, Terao H, Rikihisa W, Urabe K, Kinukawa N, Nose Y, et al. Clinical dose and adverse effects of topical steroids in daily management of atopic dermatitis. $\mathrm{Br} \mathrm{J}$ Dermatol. 2003;148(1):128-33.

7. Yohn JJ, Weston WL. Topical glucocorticosteroids. Curr Probl Dermatol.1990;2:-31-63.

8. Hengge UR, Ruzicka T, Schwartz RA, Cork MJ. Adverse effects of topical glucocorticosteroids. J Am Acad Dermatol. 2006; 54(1):1-15. 
9. Bath-Hextall F, Leonardi-Bee J, Smith C, Meal A, Hubbard R. Trends in incidence of skin basal cell carcinoma. Additional evidence from a UK primary care database study. Int $\mathrm{J}$ Cancer. 2007;121(9):2105-8.

10. Battistini E, Battistini S \& Barachini P. Epidemiology of melanoma and Non melanoma skin cancer in the provinces of Pisa and Massa-Carrara from 1997 to 2002. Gi Ital Dermatol e Venereo. 2005; 140(1): 33-44.

11. Demers AA, Nugent Z, Mihalcioiu C, Wiseman MC, Kliewer EV. Trends of nonmelanoma skin cancer from 1960 through 2000 in a Canadian population. J Am Acad Dermatol. 2005; 53(2):320-8.

12. Hol SA, Malinovszky, $\mathrm{K} \&$ Roberts $\mathrm{DL}$. Changing trends in non-melanoma skin cancer in South Wales, 1988-98. Br J Dermatol. 2000; 143(6):1224-9.

13. Staples MP, Elwood M, Burton RC, Williams JL, Marks R, Giles GG. Non-melanoma skin cancer in Australia: the 2002 national survey and trends since 1985. Med J Aust. 2006; 184(1):6-10.

14. Internet: http://www.who.int/uv/faq/skincancer/en/index1.html Internet [last accessed-2nd June 20168 $8^{\text {th }}$ December 2017].

15. Chen ST, Geller AC, Tsao H. Update on the Epidemiology of Melanoma. Current dermatology reports. 2013; 2(1):24-34.

16. Internet: http://www.cancerresearchuk.org/health-professional/cancerstatistics/mortality\#neading-Five Internet [last accessed 2nd February 20168 $8^{\text {th }}$ December 2017].

17. Karagas MR, Cushing GL, Greenberg ER, Mott LA, Spencer SK, Nierenberg DW. Nonmelanoma skin cancers and glucocorticoid therapy. Br J of Cancer. 2001. 85(5): 683-6.

18. Elmets CA. Oral Corticosteroids do not increase the incidence of non-melanoma skin cancers. MD reviewing Baibergenova, A.T. et al. 2012. Oral prednisone use and risk of keratinocyte carcinoma in non-transplant population. The VATTC trial. J Eur Acad Dermatol Venereol. 2012; 26:1109

19. Hagströmer L, Ye W, Nyrén O, Emtestam L. Incidence of cancer among patients with atopic dermatitis. Arch Dermatol. 2005;141(9):1123-7.

20. Wang H, Diepgen TL. Atopic dermatitis and cancer risk. Br J Dermatol. 2006;154(2):205-10.

21. Comeau S, Jensen L, Cockfield SM, Sapijaszko M, Gourishankar S. Non-melanoma skin cancer incidence and risk factors after kidney transplantation: A canadian experience. Transplantation. 2008; 86(4):535-41.

22. Ducroux E, Boillot O, Ocampo MA, Decullier E, Roux A, Dumortier J, et al. Skin cancers after liver transplantation: Retrospective single-center study on 371 recipients. Transplantation. 2014; 98(3):335-40.

23. Delgado M, Fernandez R, Paradela M, De La Torre M, Gonzalez D, Garcia JA, et al. Development of Neoplasms During Lung Transplantation Follow-up. Transplantation Proceedings. 20088 November; 40(9):3094-6. PubMed PMID: 2008537140.

24. Hung RKY, Cronin A, Rebollo Mesa I, Frame S, Wain EM. Skin cancer and immunosuppression in long-term renal transplant recipients: A retrospective and casecontrolled analysis. British J Dermatol. 2014; 171:108-108.

25. Coutinho AE, Chapman KE. The anti-inflammatory and immunosuppressive effects of glucocorticoids, recent developments and mechanistic insights. Molecular and Cellular Endocrinology. 2011; 335(1):2-13. 
24.26. Coondoo A, Phiske M, Verma S, Lahiri K. Side-effects of topical steroids: A long overdue revisit. Indian Dermatology Online Journal. 2014; 5(4):416-25.

25.27. Muranushi C, Olsen CM, Pandeya N, Green AC. Aspirin and nonsteroidal antiinflammatory drugs can prevent cutaneous squamous cell carcinoma: a systematic review and meta-analysis. J Invest Dermatol. 2015;135(4):975-83

26.28. Wilson JC, Murray LJ, Hughes CM, Anderson LA. Non-steroidal anti-inflammatory drug and aspirin use and the risk of malignant melanoma - A systematic review and metaanalysis. Pharmacoepidemiology and Drug Safety. 2012 August;21:419. PubMed PMID: 70936062.

27.29. Griffiths C, Barker J, Bleiker T, Chalmers R, Creamer D. Rook's Textbook of Dermatology, 4 Volume Set, 9th Edition. Wiley-Blackwell. 2016.

28.30. Williams H, Bigby M, Herxheimer A, Naldi L, Rzany B, Dellavalle R, Ran Y, Furue M. Evidence-Based Dermatlogy, 3rd Edition. Wiley-Blackwell. 2014.

29.31. Ratib S, Burden-Teh E, Leonardi-Bee J, Harwood C, Bath-Hextall F. Long-term corticosteroid use and risk of skin cancer: a systematic review protocol. JBI Database System Rev Implement Rep. 2016; 14_(12):64-73.

30.32. Landi MT, Baccarelli A, Calista D, Fears TR, Landi G. Gucocoticoid use and melanoma risk. Int J Cancer. 2001; 94(2):302-3.

31.33. Raffin D, Giraudeau B, Mahtab S, Machet L, Pourrat X, Maruani A. Corticsteroid Phobia Among Pharmacists Regarding Atopic Dermatitis in Children: A National French Survey. Acta Derm Venereol. 2016; 96(2):177-180.

32.34. Bornstein JS, Heifetz Y, Kellner Z, Stolar \& Abramovici H. Clobetasol dipropionate $0.05 \%$ versus testosterone propionate $2 \%$ topical application for severe vulvar lichen sclerosus. Am J Obstet Gynecol. 1998; 178(1); ; $80-4$.

33.35. Bouyssou-Gauthier ML, Boulinguez S, Dumas JP, Bedane C \& Bonnetblanc JM. Penile lichen sclerosus and atrophicus: Follow-up study. [French] Lichen sclereux genital masculin: Etude de suivi. Ann Dermatol Venereol. 1999; 126(11);-804-807.

34.36. Carbone M, Arduino PG, Carrozzo M, Gandolfo S, Argiolas MR, Bertolusso G, et al. Course of oral lichen planus: a retrospective study of 808 northern Italian patients. Oral Dis. 2009; 15(3):- 235-43.

35.37. Carli P, Cattaneo A, De Magnis A, Biggeri A, Taddei G \& Giannotti B. Squamous cell carcinoma arising in vulval lichen sclerosus: a longitudinal cohort study. Eur $\mathrm{J}$ Cancer Prev. $1995 ; 4 \underline{(6)} ; ;$ 491-5.

36.38. Chainani-Wu NS, Silverman Jr, Lozada-Nur F, Mayer P \& Watson JJ. Oral lichen planus: patient profile, disease progression and treatment responses. JADA. 2001;-132(7):; 901-9.

37.39. Cooper SM, Gao XH, Powell JJ \& Wojnarowska F. Does treatment of vulvar lichen sclerosus influence its prognosis? Arch Dermatol . 2004; 140(6):; 702-6.

38.40. Cooper SM \& Wojnarowska F. Influence of treatment of erosive lichen planus of the vulva on its prognosis. Arch Dermatol. 2006; 142(3):-289-294.

39.41. Edmonds E VJ, Hunt S, Hawkins D, Dinneen M, Francis N \& Bunker CB. Clinical parameters in male genital lichen sclerosus: A case series of 329 patients. J Eur Acad Dermatol Venereol._2012; $;$ 26(6):; 730-737.

40.42. Grivas N. Penile lichen sclerosus: An enigmatic and challenging disease. Urology Annals. 2015; $=7(3): ; 308-309$.

41.43. Hela Z, Samy F, Rym B, Hajlaoui K, Hayet M, Mohamed BA \& Incaf M. Genital lichen sclerosus. [French] Lichen sclereux genital. Tunisie Medicale. 2015; 
42.44. Kantere D, Lowhagen CB, Alvengren G, Maneskold A, Gillstedt M \& Tunback P. The clinical spectrum of lichen sclerosus in male patients - a retrospective study. Acta DermatoVenereol. 2014:- 94(5):; 542-6.

43.45. Kaplan I, Ventura-Sharabi Y, Gal G, Calderon S \& Anavi Y. The Dynamics of Oral Lichen Planus: A Retrospective Clinicopathological Study. Head and Neck Pathology. 2012;6(2):-178-183.

44.46. Kirtschig G, Wakelin SH \& Wojnarowska F. Mucosal vulval lichen planus: outcome, clinical and laboratory features. [Erratum appears in J Eur Acad Dermatol Venereol. 2005 Jul;19(4):530]. J Eur Acad Dermatolo Venereol. 2005;19(3):; 301-7.

45.47. Laeijendecker R, Van Joost T, Kuizinga MC, Tank B \& Neumann HAM. Premalignant nature of oral lichen planus. Acta Dermato-Venereol. 2005; 85(6):-; 516-520.

46.48. Lee A, Bradford J \& Fischer G. Long-term Management of Adult Vulvar Lichen Sclerosus: A Prospective Cohort Study of 507 Women. JAMA Dermatology. 2015;151(10):-1061-7.

47.49. Mignogna MD, Fedele S, Lo Russo L, Mignogna C, de Rosa G \& Porter SR. Field cancerization in oral lichen planus. Eur J Surg. 2007; 33, 383-389.

48.50. Murina F, Rehman S, Di Francesco S, Mantegazza V, Felice R \& Bianco V. Vulvar lichen sclerosus: A comparison of the short-term topical application of clobetasol dipropionate $0.05 \%$ versus mometasone furoate $0.1 \%$. Journal of Lower Genital Tract Disease. 2015; 19(2): $:$ 149-151.

49.51. Ogmundsdottir HM, Hilmarsdottir H, Bjornsson J \& Holbrook WP. Longitudinal study of TP53 mutations in eight patients with potentially malignant oral mucosal disorders.J Oral Pathol Med . 2009; 38 (9):; 716-721.

50.52. Petti PF, Bagan Sebastian JV, Scully C \& Chaparro N. Malignant turn of oral lichen planus in three new cases. [Spanish, English] Transformacion maligna del liquen plano oral en tres nuevos casos. Acta Otorrinolaryngol Esp. 2004; 55(1):; 41-44.

51.53. Powell J \& Wojnarowska F. Childhood vulvar lichen sclerosus. The course after puberty.J Reprod Med. 2002; 47(9):; 706-9.

52.54. Raj G. \& Bell HK. A multi-centre audit on genital lichen sclerosus in the North West of England. J Eur Acad Dermatol Venereol. 2014; 28(7):; 963-6.

53.55. Renaud-Vilmer C, Cavelier-Balloy B, Porcher R \& Dubertret L. Vulvar lichen sclerosus: effect of long-term topical application of a potent steroid on the course of the disease. Arch Dermatolo. 2004; 140(6):; 709-12.

54.56. Santegoets LAM, Helmerhorst TJM \& Van Der Meijden WI. A retrospective study of 95 women with a clinical diagnosis of genital lichen planus. Journal of Lower Genital Tract Disease. 2010; 14(4):- 323-328.

55.57. Shen ZY, Liu W, Feng JQ, Zhou HW \& Zhou ZT. Squamous cell carcinoma development in previously diagnosed oral lichen planus: de novo or transformation? Oral Surg Oral Med Oral Pathol Oral Radiol Endod. 2011; 112(5):-; 592-6.

56-58. Silverman Jr S, Gorsky M \& Lozada-Nur F. A prospective follow-up study of 570 patients with oral lichen planus: persistence, remission, and malignant association. Oral Surg Oral Med Oral Pathol. 1985; 60(1):-30-34.

57.59. Silverman Jr S \& Bahl S. Oral lichen planus update: clinical characteristics, treatment responses, and malignant transformation. Am J Dentist. 1997; 10(6) ${ }_{i ;}$ 259-63.

58.60. Simonart T, Lahaye M \& Simonart JM. Vulvar lichen sclerosus: effect of maintenance treatment with a moisturizer on the course of the disease. Menopause. 2008; 15(1):; 74-7. 
59-61. Zawislak AA, Price JH, Dobbs SP, McClelland HR \& McCluggage WG. Contemporary experience with the management of vulval intraepithelial neoplasia in Northern Ireland. Int $\mathrm{J}$ Gynecol Cancer. 2006; 16(2):; 780-785.

60.62. Ming ME, Levy R, Hoffstad O, Filip J, Abrams BB, Fernandez C, Margolis DJ. The lack of a relationship between atopic dermatitis and non melanoma skin cancers. JAAD. 2004; 50(3):357-62.

61.63. Chen YJ, Wu CY, Chen TJ, Shen JL, Chu SY, Wang CB, Chang YT. The risk of cancer in patients with psoriasis: A population-based cohort study in Taiwan. JAAD. 2011; 65(1):84-91.

62.64. Roelofzen JHJ, Aben KKH, Van Der Valk PGM, Van Houtum JLM, Van De Kerkh of PCM, Kiemeney LALM. Coal tar in dermatology. J Dermatolog Treat. 2007; 16(6):329-334. 


\section{Appendix 1: Search Strategy for Medline using OVID}

1. Epidemiologic studies/

2. Exp Case-control studies/

3. Exp Cohort studies/

4. Epidemiologic\$ stud\$.mp.

5. Case control stud\$.mp.

6. Cohort stud\$.mp.

7. Cohort analy\$.mp.

8. Follow up stud\$.mp.

9. Observational stud\$.mp.

10. Longitudinal.mp.

11. Retrospective.mp.

12. Cross sectional stud\$.mp.

13. Cross Sectional Studies/

14. Exp Observational Study/

15. $\mathrm{Or} / 1-14$

16. Carcinoma, Basal Cell/

17. Neoplasms, Basal Cell/

18. Basal Cell Nevus Syndrome/

19. Basal cell carcinoma\$.mp.

20. Basal cell cancer\$.mp.

21. Basal cell neoplasm\$.mp.

22. Nodular BCC.mp.

23. Naevoid BCC.mp.

24. Gorlin syndrome.mp.

25. Basal cell Epithelioma\$.mp.

26. Basalioma\$.mp.

27. BCC.mp.

28. Rodent ulcer\$.mp.

29. Or/16-28

30. Exp Neoplasms, Squamous cell/

31. Exp Carcinoma Squamous Cell/

32. Squamous cell carcinoma\$.mp.

33. Squamous cell cancer\$.mp.

34. Squamous cell neoplasm\$.mp.

35. Bowen disease.mp.

36. Planocellular carcinoma\$.mp.

37. sCC.mp.

38. $\mathrm{Or} / 30-37$

39. Skin neoplasms/

40. NMSC.mp.

41. Non melanoma skin cancer\$.mp.

42. Skin cancer\$.mp.

43. Skin tumo\$.mp.

44. Skin neoplasm\$ 
45. Exp Keratinocytes/

46. Keratinocytes.mp.

47. Or/39-46

48. Melanoma/

49. Melanoma.mp.

50. Or/48-49

51. topical corticosteroid\$.mp.

52. steroid\$.mp.

53. corticosteroid\$.mp.

54. exp Glucocorticoids/

55. alclometasone.mp.

56. alclomethasone.mp.

57. amcinonide.mp.

58. beclometasone.mp.

59. beclomethasone.mp.

60. exp Beclomethasone/

61. betametasone.mp.

62. betamethasone.mp.

63. exp Betamethasone/

64. clobetasol.mp.

65. exp Clobetasol/

66. clobetasone.mp.

67. desonide.mp.

68. exp Desonide/

69. desoximetasone.mp.

70. exp Desoximetasone/

71. diflorasone.mp.

72. diflucortolone.mp.

73. exp Diflucortolone/

74. fludroxycortide.mp.

75. flumetasone.mp.

76. flumethasone.mp.

77. exp Flumethasone/

78. fluocinolone.mp.

79. exp Fluocinolone Acetonide/

80. fluocinonide.mp.

81. exp Fluocinonide/

82. fluocortolone.mp.

83. exp Fluocortolone/

84. flurandrenolide.mp.

85. flurandrenolone.mp.

86. exp Flurandrenolone/

87. fluticasone.mp.

88. halcinonide.mp.

89. exp Halcinonide/

90. halobetasol.mp. 


\section{5}

536

537

538

539

540 (l"carcinoma basocelular" or "epitelioma basocelular" or "squamous cell" or "squamous cells" or 541

91. halometasone.mp.

92. hydrocortisone.mp.

93. exp Hydrocortisone/

94. methylprednisolone.mp.

95. exp methylprednisolone/

96. mometasone.mp.

97. triamcinolone.mp.

98. exp Triamcinolone/

99. Or/51-98

100. 15 AND (29 OR 38 OR 47 OR 50) AND 99

\section{Appendix 2: Search strategy for LILACS}

"epitelioma espinocelular" or "basal cell" or "basal cells" or "rodent ulcer" or "rodent ulcers" or basalioma or nmsc or "non melanoma skin cancer" or "non melanoma skin cancers" or bcc or "gorlin syndrome" or "bowen's disease" or "enfermedad de Bowen" or "planocellular carcinoma" or "planocellular carcinomas" or scc or melanoma or keratinocyte $\$$ or "skin cancer" or "skin cancers" or "skin tumor" or "skin tumours" or "skin neoplasm" or "skin neoplasms") and (alclometasone or alclomethasone or amcinonide or beclometasone or beclomethasone or betamethasone or betametasone or budesonide or clobetasol or clobetasone or desonide or desoximetasone or dexamethasone or diflorasone or diflucortolone or fluclorolone or fludroxycortide or flumethasone or flumetasone or fluocinolone or fluocinonide or fluocortin or fluocortolone or fluprednidene or flurandrenolide or flurandrenolone or fluticasone or halcinonide or halobetasol or halometasone or hydrocortisone or masipredone or methylprednisolone or mometasone or prednicarbate or triamcinolone or ulobetasol or ((topical or topica) and (steroid\$ or corsticosteroid\$ or

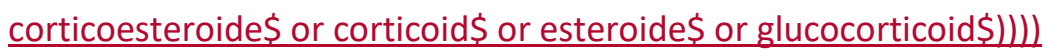


561

562

563

564

565

566

567 